\title{
UN DELITO PROPIO. ANÁLISIS CRÍTICO DE LOS FUNDAMENTOS DE LA LEY DE FEMICIDIO
}

\author{
A crime of one's own. \\ Critical analysis of the foundations of the law of femicide
}

Nicolás Ried S.*

\begin{abstract}
Resumen: A pesar de lo enunciado en los fundamentos de la creación del delito de femicidio, el objeto jurídico que se protege no es la víctima llamada "mujer", sino una institución que la absorbe y la supera, a saber, la familia, particularmente aquello que se llama "el orden de las familias". La pretensión de este trabajo consiste en revelar cuáles son las implicancias políticas y éticas, desde una perspectiva crítica, de la creación del delito especial de femicidio, considerando principalmente los argumentos del feminismo y del posfeminismo.
\end{abstract}

Palabras clave: femicidio - incesto - familia - teoría Queer.

Abstract: Despite the stated rationale for creating the crime of femicide, the legally protected is not the victim called "woman", but an institution that absorbs her and goes beyond, namely the family, particularly that which is called "the family order". The aim of this work is to reveal what they are, from a critical perspective, political and ethical implications of the creation of the special offense of femicide, mainly considering the arguments of feminism and post-feminism.

Keywords: femicide - incest - family - queer theory.

La discusión teórica sobre el femicidio abarca diversos aspectos: la diferencia lingǘstica en el uso de "femicidio" o "feminicidio"; la consagración jurídica de los diversos tipos de femicidio; ${ }^{2}$ los casos sociológicamente y periodísticamente

\footnotetext{
* Alumno Facultad de Derecho, Universidad de Chile. Correo electrónico: nicolasried@hotmail.com

1 En este artículo se hablará solamente de "femicidio", esquivando la discusión semántica en relación con "feminicidio". Por lo pronto, la diferencia entre ambos conceptos consiste en que femicidio equivale a homicidio, o sea, dar muerte a una mujer; en cambio, feminicidio daría cuenta del asesinato en función del género de la víctima mujer. Además, hay un uso teórico para feminicidio que asocia los crímenes sistemáticos de mujeres a la inactividad estatal, lo que responsabiliza al Estado por los mismos.

${ }^{2}$ Existen diversos tipos de femicidio, en sus usos teóricos: femicidio íntimo, femicidio no íntimo, femicidio por conexión, feminicidio, suicidio femicida, femicidio sexual, femicidio sistémico. Lo que aquí hay que tener en cuenta es que el femicidio que consagra la ley chilena es femicidio intimo, es decir, comprende los asesinatos cometidos por hombres con quien la víctima tenía o tuvo una relación íntima, familiar, de convivencia u otras afines.
} 
interesantes de femicidios. Lo que aquí interesa, sin embargo, es inspeccionar los fundamentos que explican la creación de un nuevo tipo penal en el ordenamiento legal chileno en 2010.

Se adelantan dos tesis, de las cuales sólo una será aquí desarrollada de manera extensa: (1) el objeto jurídico protegido por esta ley no es la mujer como fin en sí, sino el orden de las familias; (2) no corresponde a un sistema penal establecer castigos según las contingencias sociales, ni tampoco establecer símbolos de lucha política, pues para eso existen otras instancias democráticas. La primera de las tesis es la que en este artículo se argumenta, la segunda sólo sirve de axioma.

Desde su conceptuación por parte del feminismo de la segunda ola, el femicidio ha sido entendido como un crimen terrorista producido por la misoginia intrínseca que los hombres desarrollan en un sistema de dominación patriarcal ${ }^{3}$. En definitiva, el odio es el principal motor de este delito, ya sea odio producido por una relación amorosa fallida o bien por mero resentimiento en contra del género femenino, siempre sin embargo el odio está dentro de un hombre. Ciertamente, esta concepción que esencializa los géneros (a las mujeres como víctimas y a los hombres como victimarios) no puede servir de sustento para la formulación de un sistema jurídico penal: el derecho no se puede hacer cargo de odios ni amores, por ser estos criterios de carácter privado o estados mentales a los que no se puede acceder.

Es en este contexto, en que la lucha política llevada a cabo por el feminismo ha conseguido que en nuestro país se apruebe la ley que tipifica al delito especial de femicidio como una variante del parricidio. Si bien no existen diferencias en cuanto a pena entre un parricida y un femicida, se entiende que es un triunfo simbólico: la inserción en el lenguaje jurídico de la violencia en contra de las mujeres como una realidad es un triunfo. La pregunta importante es, ¿hasta qué punto es un triunfo?

Una posible respuesta es la de entender este proceso como parte de la resignificación del discurso relativo a la violencia de género, más conocida como violencia en contra de la mujer. Esta tesis muestra que el reconocimiento de nuevas instituciones que integren a las minorías sirve como parte del progreso de la ciudadanía, un proceso de extensión de los derechos ciudadanos que permite luchar por otros bienes mayores ${ }^{4}$. Si bien esta idea permite dar cuenta de cómo las luchas por el matrimonio entre personas del mismo sexo o por la inserción de un delito de femicidio no son contradictorias para el movimiento gay (quienes consideran tradicionalmente que la institución familiar es un lugar de opresión) y el

\footnotetext{
${ }^{3}$ Russell, Diana, "Conclusión feminicidio: la 'solución final' de algunos hombres para las mujeres"; en, de la misma, Femicidio: una perspectiva global, ed. Unam, 1992, p. 346.

4 Paternotte, David, “Matrimonio 'homosexual' y ciudadanía: la hipótesis de la resignificación”, en: Revista Nomadias, Santiago, 2012.
} 
feminismo (quienes, en alguna de sus vertientes, consideran que hombres y mujeres deben tener los mismos derechos), no apunta certeramente al objeto de la lucha: con esto no se pretende que aquellos que son "minoritarios" o "más débiles" se integren a las instituciones de "todos", sino al contrario, romper con la diferencia entre los "menos" y "todos"; una modificación del paradigma de las relaciones sociales, una nueva concepción de la fraternidad, no una mera participación conjunta desde la diferencia.

El presupuesto de todos quienes defienden el femicidio es propiamente discutible, incluso indeseable: existen diferentes sexos, jerárquicamente organizados, uno más fuerte que otro; la mujer es el sexo débil.

Se argumentará por qué la tipificación del femicidio no es tan un triunfo como parece, teniendo como base la tesis central: la mujer no es (ni debe ser) objeto de protección de la ley, sino sólo un medio para sostener un sistema ordenado de la sexualidad. No se sostendrá, sin embargo, que este acto político sea una derrota y que el mundo sería mejor sin esta nueva norma; al contrario, la publicación de esta ley permite al fin reflexionar sobre los temas de fondo: ¿cuáles son las normas jurídico-morales constitutivas de lo sexual?, ¿existe manera de disociar sexo y género en un sistema jurídico?, ¿es necesario mantener marcadores de sexo/género en las leyes?, ¿qué función jurídica tiene el hecho de hablar de "hombres" y "mujeres"?, ¿es imaginable un sistema jurídico que no contemple divisiones sexuales; cuáles serían sus implicaciones?

\section{La ley de "femicidio"}

La Ley 20.480 de 2010 crea el delito de femicidio, refiriéndose con este término a un delito especial de parricidio, el cual puede ser descrito como: "el hombre que, conociendo las relaciones que los ligan, mate a una mujer que es o ha sido su cónyuge o su conviviente, cometerá el delito de femicidio". ${ }^{5}$ Es de destacar que la pena para el femicidio es idéntica a la pena para el parricidio en las mismas circunstancias, lo que da cuenta del carácter radicalmente simbólico de la incorporación de aquel al sistema jurídico chileno.

Esta iniciativa aparece como la reacción frente al fenómeno del asesinato sistemático de mujeres, cometido a manos de los hombres con los que estaban ligadas en relaciones amorosas, en vías de parentesco o de familia (i. e. femicidio íntimo). Intentaré mostrar cómo, a pesar de lo enunciado en los fundamentos de

\footnotetext{
5 Tal descripción se obtiene revisando el artículo 390 del Código Penal, que define el parricidio como delito: "El que conociendo las relaciones que lo ligan, mate a su padre, madre o hijo, a cualquier otro de sus ascendientes o descendientes o a quien es o ha sido su cónyuge o su conviviente, será castigado como parricida [...]"; en conjunto con la modificación de la mencionada ley, que agrega en párrafo aparte: "Si la víctima del delito descrito en el inciso precedente es o ha sido la cónyuge o la conviviente de su autor, el delito tendrá el nombre de femicidio".
} 
esta modificación, el bien jurídico que se protege no es la víctima llamada "mujer", sino una institución que la absorbe y la supera, a saber: la familia, particularmente aquello que se denomina "el orden de las familias". Es sobre esta tesis de donde se obtiene la descripción mencionada del nuevo tipo de femicidio, en que es la mujer el sujeto pasivo del delito: un determinado concepto de lo familiar, sumado al entendimiento de la mujer como "el sexo débil", impiden visibilizar como particulares descripciones los asesinatos de mujeres a hombres en función de su género y entre hombres o entre mujeres, invisibilizando la existencia de relaciones íntimas lésbicas-gay. ${ }^{6}$

En el boletín $\mathrm{N}^{\circ}$ 4937-18 que modifica el Código Penal y el decreto ley $\mathrm{N}^{\circ} 321$, de 1925, que sanciona el femicidio, se describen los fundamentos que motivan la creación de este delito especial (y otras modificaciones), ${ }^{7}$ entre los que destacan el gran impacto que ha producido la excesiva violencia mostrada en los medios de comunicación, principalmente los ilícitos que, circunscritos al plano familiar, tienen como víctimas a mujeres, en el marco de relaciones de pareja. ${ }^{8}$ Tales delitos, cometidos en contra de mujeres, han explotado cuantitativamente desde el año 2007 hasta hoy, lo que sumado a una insuficiente legislación al respecto impide una adecuada protección a la integridad de aquel conjunto de la población conocido como "el sexo débil". Al no existir una conceptuación adecuada, defiende el proyecto de ley, se da el caso de que los victimarios atenúen

\footnotetext{
${ }^{6}$ Agradezco al Dr. Juan Pablo Mañalich, a quien mucho estimo, por mostrarme que este punto no estaba del todo claro, en la exposición que de este trabajo hice en el Primer Encuentro de Derecho Penal y Política Criminal, 2011.

${ }^{7}$ Las modificaciones que establece la ley son: Tipificación del delito de femicidio, cuando la víctima del parricidio es una mujer que es o ha sido cónyuge o conviviente del autor; inclusión de los ex cónyuges o ex convivientes dentro del delito de parricidio, lo que permite que tengan igual pena los hombres o mujeres que asesinen a sus ex parejas; se establece una eximente de responsabilidad penal para el que obre para evitar un mal grave para su persona o un tercero, cumpliéndose determinados requisitos; para poder aplicar irreprochable conducta anterior al imputado por cualquier delito, se obliga a los jueces a considerar los antecedentes previos por violencia intrafamiliar que éste pudiera tener; se autoriza a prescindir de la autorización del padre o madre que ha sido condenado por delitos sexuales, cuando se quiere sacar a los hijos del país; se duplica el periodo de duración de las medidas accesorias a la sentencia para agresores en causas de violencia intrafamiliar, ampliándose éstas hasta dos años. Ejemplos: prohibición de acercarse a la víctima, obligación de asistir a terapia, etc.; se incorpora dentro de las presunciones de riesgo para una víctima de violencia intrafamiliar, la negativa violenta de aceptar el término a una relación de pareja; el juez de familia queda obligado a entregar medidas cautelares a la víctima de violencia intrafamiliar antes de remitir la causa al ministerio público, eliminando así uno de los períodos más riesgosos para las víctimas de violencia intrafamiliar; se agravan las penas por delitos sexuales, cuando estos son cometidos por dos o más personas.

${ }^{8}$ Los femicidios íntimos, o sea, aquellos cometidos por un hombre que tenía alguna relación de afecto, familiar o afín con la víctima, ocupan más del 90\% de los casos, que entre los años 2007 y 2009 superaron las 50 víctimas anuales, según el estudio "Violencia intrafamiliar en cifras" de 2010 hecho por SERNAM y disponible en: http://www.sernam.cl/portal/images/documentos/campania maltrato2010/vif cifras.pdf. Esto, sin duda, es lo que Judith Butler conceptúa como marcos de violencia, ver Butler, Judith, Violencia de Estado, guerra, resistencia. Por una nueva politica de la izquierda, Ed. Katz, Madrid, 2011.
} 
y minimicen las penas que les corresponden por el delito, lo que da cuenta de una intención radicalmente prevencionista en la implementación de la ley, cuyo principal motivo de ser es la contingente reducción de delitos. ejes: ${ }^{9}$

Es en ese sentido que el proyecto de ley propone modificaciones sobre tres

1.- Incorporación conceptual del femicidio a los tipos penales chilenos, lo que se supone que implicaría un cambio lingüístico-cultural tendiente a la evitación de los delitos cometidos contra las mujeres por hombres con los que han entablado algún tipo de relación afectiva.

2.- Disminución de las posibilidades de aplicar la atenuante de "obrar por estímulos tan poderosos que naturalmente hayan producido arrebato y obcecación en algunos delitos cuando el agresor ha sido sancionado previamente por violencia intrafamiliar". Lo anterior se justifica, según el boletín, ya que "no es posible pensar en una sociedad que disculpe todos y cada uno de los arrebatos de una persona que no logra reprimir sus impulsos y que encauza su irracionalidad en contra de sus seres más queridos".

3.- Eliminación de la posibilidad de acceder a la libertad condicional a los condenados por delitos especialmente graves de connotación familiar, particularmente el femicidio. La comisión de delitos como el parricidio y el femicidio, dice el boletín, son crímenes en que ha sucedido una larga serie de atropellos y maltrato, constitutivos de violencia doméstica, que "ameritan una sanción ejemplarizadora, en tanto el autor ha atentado contra la esfera de seguridad más íntima de la víctima y causado un daño irreparable a los restantes miembros de su núcleo familiar'. ${ }^{10}$

Tras analizar los fundamentos y propuestas de lo que era el proyecto de ley de la actual modificación que crea el delito de femicidio, podemos evidenciar cuáles son los objetos de protección o bienes jurídicos protegidos por esta legislación y así revelar a qué objetivos políticos y éticos atiende esta modificación legal.

Ciertamente, debemos entender que la protección no apunta directamente a las mujeres, al menos no como fin en sí mismo, sino que apunta a la protección de la institución de la familia, en tanto "núcleo familiar". "Ello queda en evidencia cuando no protege todo tipo de violencia a mujeres, sino que solamente aquella realizada por hombres que han tenido relaciones afectivas con dichas y determinadas mujeres. Tal limitante es importante, ya que da nuevas luces de qué debe entenderse por "familia" en la silente legislación chilena, puesto que

\footnotetext{
9 Boletín $\mathrm{N}^{\circ}$ 4937-18, que modifica el Código Penal y el decreto ley $\mathrm{N}^{\circ}$ 321, de 1925, para sancionar el femicidio y aumentar las penas aplicables a este delito.

${ }^{10}$ Ibid., punto C.

${ }^{11}$ Lo que viene a ser lo mismo en algún sentido: proteger a las mujeres en tanto incubadoras de humanos, reproductoras de la familia, en definitiva objetos.
} 
obtenemos algunos conceptos del tipo: una afectación al núcleo familiar no se puede dar entre personas del mismo sexo, validando la matriz heteronormativa que constituye las relaciones de parentesco jurídicamente $;{ }^{12}$ por otra parte, valida ciertas formas de convivencia familiar entre estas personas de distinto sexo, a saber, que exista al menos una relación de "afecto", sino "convivencia" o derechamente "matrimonio"; además, la pretensión de que la creación de este tipo especial sea una prohibición de asesinar mujeres que se levante como una "sanción ejemplarizadora" que logre disuadir la violencia familiar provocada por un faloportador, se compromete férreamente con una determinada concepción discursiva jurídica-penal: el prevencionismo general, ${ }^{13}$ como una suerte de política criminal que entiende la función del derecho como una herramienta que soluciona problemas sociales.

La pretensión de este trabajo es revelar cuáles son las implicancias políticas y éticas, desde una perspectiva crítica, de la creación del tipo especial de femicidio, considerando principalmente los argumentos del feminismo y el posfeminismo. ${ }^{14}$

\section{Implicancias teóricas de la publicación de la ley}

El derecho penal, como fuente de constitución de sujetos, funciona principalmente a través de la prohibición normativa. El discurso jurídico, en ese sentido, se impone como un sistema gramatical constructor de identidad, de determinación de lo correcto y lo incorrecto, de limitación de lo corporal y -en lo que me enfocaré en el presente trabajo- de normalización de los sujetos: un sistema que performa el mundo. Una explicación distinta para la misma idea es la del reproche jurídicopenal como reconocimiento del sujeto, ${ }^{15}$ que entiende que la pena es una respuesta ante una declaración performativa que niega al Derecho, y no como una reacción espontánea ante una situación contingente.

La creación de un delito especial de "femicidio" apuesta por y se compromete con una serie de supuestos, que son de muy difícil argumentación si se contextualiza al discurso jurídico-penal en un conjunto de principios, llámense "democráticos", "pluralistas, "liberales" o incluso "feministas". La revelación y reestructuración de los compromisos del acto político de especializar el delito de homicidio (o, más bien, parricidio) cometido en contra de una mujer, en su condición de tal, es el elemento que hace posible el avance hacia una política

\footnotetext{
12 Butler, Judith, El género en disputa, Paidós, Barcelona, 2007, p. 72.

${ }^{13}$ Ferrajoli Luigi, Derecho y razón. Teoría del galantismo penal, Trotta, Madrid, 2001, pp. 275 y ss.

${ }^{14}$ Cf. De las Heras, Samara, "Una aproximación a las teorías feministas", Universitas. Revista de Filosofía, Derecho y Política, No 9, enero 2008, pp. 45 - 82.

${ }^{15}$ Cf. Mañalich, Juan Pablo, Terror, pena y amnistía, ed. Flandes Indiano, Santiago, Chile, 2010, pp. 87 y ss.; Mañalich, Juan Pablo, "La pena como retribución”, en Revista de Estudios Públicos No 108, Santiago, 2007.
} 
REJ - Revista de Estudios de la Justicia - No 16 - Año 2012

posfeminista que prescinda de la agotada distinción entre "sexo" y "género", incluyendo las categorías normalizadoras que esta distinción implica.

Así, el reforzamiento de la prohibición de asesinar a una mujer, por su condición de tal, implica:

Primero, una valoración de lo masculino por sobre lo femenino, en función de que lo segundo es un objeto de lo primero, y como objeto valioso funcionalmente, merece ser protegido de manera especial, tal como el delito de abigeato ${ }^{16}$ lo hace con determinados animales considerados valiosos en un momento determinado de la historia de Chile.

Segundo, un compromiso anterior con la distinción entre un género masculino y otro femenino, o sea, con la categoría "género". Además, presenta una relación de causalidad con el concepto de "sexo", subyacente a una posible explicación del género. Así, quien presenta los elementos biológicos para ser considerado de un sexo u otro, pertenecerá al género correspondiente, pues existe una presunción del género por el sexo. ${ }^{17}$

Tercero, las explicaciones biológicas de los componentes sexuales constituyentes de un sujeto tienen como sustento argumentativo la aceptación como verdadero del discurso científico por sobre otras formas de conocer el mundo. Valida, por tanto, que "la biología es destino". ${ }^{18}$

Cuarto, la aceptación de este discurso, entendido bajo la interpretación de Foucault como una relación de poder-saber, presenta como efecto $-\mathrm{y}$ a la vez argumento del acto político de especialización del delito en cuestión- la validación de un sistema jurídico normalizador y delimitador de aquello que puede ser considerado como "sujeto" en un mundo jurídicamente determinado, en definitiva es un sistema subjetivante.

Quinto, los límites de lo corporalmente normal y, claro, de lo anormal y lo abyecto, de lo inhumano y de lo inmoral, existiendo principalmente un compromiso con una determinada concepción de lo bumano que es restrictiva y disciplinante.

Si bien el ánimo es de triunfo, como ya se ha señalado, existen críticas a la ley desde posiciones teóricas diversas, por lo pronto distintas a la que aquí se presenta desde el sistema Foucault-Butler. Así, el penalista Jorge Mera Figueroa propone que "debiera suprimirse el parricidio (sin perjuicio de la circunstancia

\footnotetext{
16 Art. 448 bis. y siguientes del Código Penal.

${ }^{17}$ Cf. Butler, Judith, El género (nota 12), pp. 55 y ss.; Mañalich, Juan Pablo, “Ontología sexual y derecho penal", en En reversa. Primeras jornadas estudiantiles de teoría de género, Universidad de Chile, ed. Párrafo, Santiago, 2011.

${ }^{18}$ Butler, Judith, El género (nota 12), p. 57.
} 
mixta del parentesco), mantenerse la distinción entre homicidio simple y calificado (revisando por cierto las calificantes) y crearse la figura del femicidio"19, ya que el parricidio no se justifica en el sistema penal chileno existiendo el tipo del homicidio calificado, pero sí se justifica un femicidio desprendido del parricidio porque "lo que lo distingue del parricidio es que se afecta la vulnerabilidad de la víctima, se trata de una cuestión de género, es la condición de mujer de la víctima la que incrementa el injusto de su homicidio". ${ }^{20}$

Desde la perspectiva de los derechos humanos de la mujer, Patsilí Toledo enmarca la ley de femicidio en el contexto de violencia en contra de las mujeres, la cual debe ser prevenida; no considera un triunfo esta nueva ley ya que "sancionar el feminicidio [sic] en Chile probablemente no permitirá reducir la tasa de estos delitos, como ninguna ley penal lo hace. Al parecer la única posibilidad de que estas cifras se reduzcan se relaciona con la más diligente actuación en los casos de violencia que aún no constituyen femicidio". ${ }^{21}$

Dejando de lado la vertiente del feminismo que piensa que esta ley es un triunfo absoluto, las concepciones mencionadas presentan deficiencias en cuanto asumen que la inserción del delito de femicidio debe ser un mecanismo que produzca cambios en el mundo real, es decir, que su fundamento es el mismo que el de una política de gobierno: es una medida que se toma para espantar a los posibles delincuentes y si se disminuye la tasa de delitos, la pena "funciona"; pero por otro lado, lo más profundo, es que dejan de lado (con excepción de Patsilí Toledo) cualquier posibilidad de entendimiento del género y del sexo como conceptos distintos: si se protegerá a "la mujer" porque "es débil", o porque "es mujer" como dice Mera, nos preguntamos: ¿es mujer porque tiene cuerpo de mujer? La respuesta no puede ser sí desde la distinción clave del feminismo de segunda oleada entre "sexo" y "género"; pero por otra parte, si la respuesta es no, no cabe duda que el motivo de la defensa a las mujeres sea producto del hecho de "ser mujeres", pues así: ¿un homosexual no es mujer?, ¿hasta qué punto un travesti sigue siendo un hombre? El entender toscamente las relaciones de género, no caben explicaciones que enmarquen al delito de femicidio en un sistema democrático, pluralista y de ciudadanía extendida, pues al contrario, sólo excluye. En palabras de Toledo: "el riesgo de una tipificación que busque establecer una penalización especial de sólo ciertas formas de violencia contra las mujeres, sin que exista una disposición que -en términos generales- sancione la misma conducta dirigida a otros sujetos, puede eventualmente dar lugar a restricciones o

\footnotetext{
19 Mera F., Jorge, "Femicidio", en: Tipificación del femicidio en Chile. Un debate abierto, ed. Andros, Santiago, 2009, p. 56.

20 Ibid., p. 55.

${ }^{21}$ Toledo, Patsilí, "Leyes sobre femicidio y violencia contra las mujeres. Análisis comparado y problemáticas pendientes", en: Tipificación del femicidio en Chile. Un debate abierto, ed. Andros, 2009, p. 50 .
} 
exclusiones de difícil justificación", 22 lo que ciertamente es el caso de Chile: ¿el asesinato de un travesti por el hecho de ser tal, puede ser considerado femicidio?, ¿puede haber femicidio íntimo hacia un homosexual? La respuesta, desde esta nueva ley, es no a ambos casos: al primero, porque no se entiende que el género pueda ser performatizado y que también pueda existir odio en contra de personas que no son mujeres; y el segundo, porque no existe en Chile matrimonio entre personas del mismo sexo aún, por tanto imposibilidad de formar familia en esas condiciones.

Sin embargo, existe un motor argumentativo que une en un sentido profundo todo el conjunto de mecanismos de poder que se manifiestan en el discurso que permite la realización del femicidio en el Derecho. Tal idea, en palabras de Judith Butler, puede entenderse como el parentesco heteronormativo, o sea, la premisa que dice que el parentesco es de antemano heterosexual, siendo eso lo que deforma las posibilidades éticas que el Derecho permite vivir. ${ }^{23}$

\section{El problema del género y la naturalización}

En la concepción de lo legal/jurídico, proveniente de Hegel, Michel Foucault caracteriza la ley como disimulo; en sus palabras: "Si estuviera presente en el fondo de uno mismo, la ley no sería ya la ley, sino la suave interioridad de la conciencia. Si por el contrario, estuviera presente en un texto, si fuera posible descifrarla entre las líneas de un libro, si pudiera ser consultado el registro, entonces tendría la solidez de las cosas exteriores: podría obedecérsela o desobedecérsela: ¿dónde estaría entonces su poder?, ¿qué fuerza o qué prestigio la haría venerable? De hecho, la presencia de la ley consiste en su disimulación". ${ }^{24}$

La ley sólo aparece cuando es atraída por un desafío, entendido en la forma de una prohibición. La ley es un golem que cobra vida con el acto: su cuerpo es ficción, pero su vida es realidad. El cuerpo de lo legal, en concreto, aparece en su negatividad, en aquello que está más allá de sus límites, precisamente aquello que contradice la prohibición. Lo legal, normaliza y disciplina corporalmente a los sujetos, define quién será la víctima y el delincuente, describe su historia y predice su delito. La ley regula las posibilidades del hacer, siendo esa la gran prohibición, ya que limita las posibilidades de existir al unirlas con las condiciones del hacer de un sujeto determinado. Como indica Butler: "Si soy alguien que no puede ser sin hacer, entonces las condiciones de mi hacer son, en parte, las condiciones de mi existencia. Si mi hacer depende de qué se me hace o, más bien, de los modos en que yo soy hecho por esas normas, entonces la posibilidad de mi persistencia

\footnotetext{
22 Toledo, Patsilí, “¿Tipificar el Femicidio?", en Anuario de Derechos Humanos No 4, Centro de Derechos Humanos, Facultad de Derecho de la Universidad de Chile, Santiago, 2008, p. 218.

${ }^{23}$ Cf. Butler, Judith, Deshacer el género, Paidós, Barcelona, 2006, pp. 149 y ss.

${ }^{24}$ Foucault, Michel, El pensamiento del afuera, ed. Pre-textos, Valencia, $5^{\text {a }}$ edición, 2004, pp. 43-44.
} 
como 'yo' depende de la capacidad de mi ser de hacer algo con lo que se hace conmigo". 25

Al definir nuestro ser mediante nuestro hacer, el discurso jurídico restringe las posibilidades de existencia de nuestras relaciones sociales en general, y de parentesco particularmente. Es en esta forma como se subsume el concepto de femicidio bajo el de parricidio: sólo un hombre con una mujer pueden estar relacionados de modo tal que la muerte dada por él a ella sea producto de sus relaciones de parentesco. Dos lesbianas convivientes, por ejemplo, no pueden cometer femicidio entre ellas; tampoco una pareja de homosexuales hombres, ni un grupo polígamo. Subyace a esto la idea de que el hacer constituye al ser, ya que las prácticas sexuales de los sujetos determinan su posición simbólica de "hombre" o "mujer", definiéndose previamente cuáles son las funciones de 'lo hombre' y de 'lo mujer', quién puede matar ante el Derecho y quién no. No existen "las femicidas" y ese es el hecho que propulsa una serie de interrogantes, como: ¿es un derecho que debe ser reconocido exclusivamente a los hombres el de asesinar de una manera particular a su mujer?, ¿siempre un cónyuge o un conviviente debe ser del "genero" opuesto?, ¿existe una relación ontológica que justifique la complementariedad de los "sexos", que sirva de base para ver algo especial en el hecho de que un hombre mate a una mujer?, ¿qué significa "convivir", cuáles son sus límites? El problema parece ser de perspectiva, ya que el Derecho nos guía lingǘsticamente con una manera de ver los hechos del mundo, entonces ¿qué hay estrictamente de especial en este tipo de asesinato por parentesco?

\section{El concepto de familia ${ }^{26}$}

Las relaciones de parentesco están normativamente estructuradas como heterosexuales y monógamas. Podemos seguir una ruta que iría desde esta matriz heterosexual sobre la cual se funda el matrimonio, institución que sostiene a la familia, institución que, a su vez, constituye el núcleo de la sociedad. Así, entendiendo el parentesco como Judith Butler, o sea como "una serie de prácticas que instituyen relaciones de varios tipos mediante las cuales se negocian la reproducción de la vida y las demandas de la muerte"27, el discurso jurídico subentiende que las relaciones sociales que tienen la potencia de ser clasificadas como "parentesco" deben cumplir con el requisito de la heterosexualidad de las prácticas y los deseos de los sujetos que las integran, y además, siendo el

\footnotetext{
${ }^{25}$ Butler, Judith, Deshacer (nota 23), p. 16.

${ }^{26}$ Un desarrollo más extenso de esta idea sobre el matrimonio en Ried, Nicolás, "Venciendo a Procusto. El concepto de familia: el feminismo liberal, el post-feminismo y el problema del género", en: Revista Derecho y Humanidades, № 17, Facultad de Derecho Universidad de Chile, Santiago, 2011, pp. 203-228; Ried, Nicolás, "Familia y prohibición. Genealogía de las prohibiciones jurídicomorales en materia sexual", en CECU, En reversa. Primeras jornadas estudiantiles de teoría de género, ed. Párrafo, Santiago, Chile, 2011.

${ }^{27}$ Butler, Judith, Deshacer (nota 23), p. 150.
} 
REJ - Revista de Estudios de la Justicia - No 16 - Año 2012

parentesco una manifestación de lo social, sólo puede constituirse de esta manera. No es que no exista parentesco homosexual, sino que algo así sería una contradicción.

El derecho, como institución que prescribe conductas y delimita lingüístico-realizativamente las instituciones que constituyen a los sujetos, establece la institución de la familia, precisamente porque ello implica definir los márgenes de lo social e incluso los límites de lo bumano, ya que entrega la óptica sobre la cual hablaremos de seres humanos relacionados. El Derecho, cumpliendo su pretensión de ser una "ciencia", es una ciencia que crea su propio objeto de estudio, establece los límites de lo existente y excluye lo contranormativo como si fuera contrafáctico. Así, si se define "familia", tal definición no tiene ánimos descriptivos, sino prescriptivos; o sea, no un concepto que englobe todos los grupos sociales que podamos entender como familia empíricamente, sino un estándar normativo que nos permita ver familias en determinados grupos sociales humanos.

Es de vital importancia para continuar revisar bajo qué estándar normativo funciona el Chile de comienzos del siglo XXI, en tanto sujetos sociales y humanos, en relación a sus relaciones familiares. El sistema legal le da una importancia sideral a la familia cuando la caracteriza como "el núcleo fundamental de la sociedad" en la Constitución Política. La definición del concepto no es entregada por la legislación, sino que es un ruido abierto a interpretaciones. Sin embargo, el sistema jurídico en su conjunto nos entrega herramientas para poder cercar y definir los límites de lo familiar. Así, en la ley de matrimonio civil se señala que: "La familia es el núcleo fundamental de la sociedad. El matrimonio es la base principal de la familia". ${ }^{28}$

Idea que tiene sus raíces en el Pacto Internacional de Derechos Civiles y Políticos de 1976, en que se indica que: "La familia es el elemento natural y fundamental de la sociedad y tiene derecho a la protección de la sociedad y del Estado. Se reconoce el derecho del hombre y de la mujer a contraer matrimonio y a fundar una familia si tienen edad para ello". ${ }^{29}$

Sobre estas normas jurídicas podemos determinar a los sujetos que son aptos para que sus relaciones sociales sean calificadas como normales dentro del sistema. Es de esta manera como se liga fuertemente a la familia con el matrimonio, y de paso se construyen las bases de la sociedad sobre esta relación: MATRIMONIO-FAMILIA-SOCIEDAD.

El matrimonio, por su parte, tiene una estructura fuertemente heteronormativa (en cuanto la imposición de las prácticas heterosexuales constituye la norma): "El matrimonio es un contrato solemne por el cual un hombre y una mujer

\footnotetext{
${ }^{28}$ Ley de matrimonio civil (Ley No 19.947, de 2004), art. 1, inciso $1^{\circ}$, Chile.

${ }^{29}$ Pacto Internacional sobre Derechos Civiles y Politicos, art. 23, incisos $1^{\circ}$ y $2^{\circ}, 1976$.
} 
se unen actual e indisolublemente, y por toda la vida, con el fin de vivir juntos, de procrear y de auxiliarse mutuamente". ${ }^{30}$

Sobre esta relación heterosexualizante de las prácticas sexuales de los sujetos que regula nuestro derecho, podemos establecer las funciones que el orden de las relaciones familiares tiene en nuestra sociedad. Así, son evidentes: primero, vivir juntos; segundo, procrear; y, tercero, auxiliarse mutuamente. Sin embargo, de estos tres elementos sólo uno de ellos es estructuralmente fundamental y se revela cada vez que se discute el tema relativo al "matrimonio homosexual", ya que sus detractores argumentan que dos hombres, por ejemplo, no pueden procrear (porque claro, sí pueden vivir juntos y auxiliarse mutuamente), olvidando que una pareja heterosexual en que uno de los dos es estéril, o incluso más, una pareja heterosexual que no quiera tener hijos, tampoco, implicando esto que debería exigirse algo así como un requisito extraordinario de entregar un hijo a la sociedad en un determinado plazo. Esto da cabida a un concepto explícitamente victoriano de la familia y su función, que, siguiendo a Foucault: "Lo que no apunta a la procreación o está transfigurado por ella ya no tiene sitio ni ley. No puede expresarse. Se encuentra a la vez, expulsado, negado y reducido al silencio. No sólo no existe sino que no debe existir y se lo hará desaparecer a la menor manifestación - actos o palabras". ${ }^{31}$

El discurso jurídico sobre el que se construyen las relaciones familiares de los sujetos normalizados establece una jerarquía de las prácticas sociales y, por lo tanto, de los mismos sujetos. Toda esta secuencia discursiva divide según sexualidad, y jerarquiza esas sexualidades, incluso excluyendo performativamente algunas de ellas. ${ }^{32}$

\section{El "sexo débil" como fundamento}

Una de las principales tesis defendidas en este trabajo es aquélla que critica la idea de mujer-víctima para justificar la existencia del tipo especial de femicidio, considerando más bien que el fundamento es el de protección a la institución de la familia.

Como se ha mostrado, la institución de la familia se convierte en el motor fundamental de la matriz heterosexual, categorizando a los sujetos según sus prácticas sexuales y jerarquizándolos según el sexo/género que se les asigne culturalmente (masculino por sobre femenino). Un determinado entendimiento de

\footnotetext{
${ }^{30}$ Código Civil, República de Chile, art. 102.

${ }^{31}$ Foucault, Michel, Historia de la sexualidad. La voluntad del saber, vol. 1, ediciones Siglo XXI, Buenos Aires, 2008, p. 10.

32 Es precisamente la idea del sujeto abyecto la que daría forma a "lo normal". Cf. Butler, Judith, Cuerpos que importan, Paidós, Bs. Aires, $2^{\mathrm{a}}$ edición, 2008, pp. 18 y ss.
} 
lo familiar define el parentesco determinando quiénes podrán acceder a él; da forma al "núcleo de la sociedad"; sacraliza determinadas formas de vida, trazando los límites de la eticidad; prescribe las funciones de los sujetos participantes de ella; y, como ya he mencionado, celebra una determinada concepción de lo bumano. Todo esto podemos evidenciarlo, al menos, desde el discurso jurídico, y preguntarnos por los fundamentos de la protección penal especial a otros bienes jurídicos, delineando así una estructura discursiva jurídico-penal de lo femenino.

Las interrogantes son: ¿por qué darle protección especial a un conjunto de sujetos de la sociedad, en este caso las mujeres?, ¿qué queremos conseguir con un cambio de este tipo? Si encontramos buenos fundamentos para hacerlo, ¿por qué a las mujeres y no a los hombres en las mismas condiciones? Si finalmente lo reducimos al sexo/género femenino, ¿esta modificación de la ley cumple con la protección promovida originalmente?

La inicial propuesta de modificación al artículo del parricidio, contemplando este delito especial de femicidio, promovía y consagró finalmente lo que podemos entender como femicidio intimo, es decir, aquel homicidio "cometido por el hombre con quien la víctima tenía o tuvo una relación íntima, familiar, de convivencia o afín". ${ }^{33}$ Esta idea reduce el entendimiento del concepto de "mujer" que se tenga, en función de dar a luz una determinada protección legal, resignificando el significante "mujer" como aquel sujeto del sexo femenino que es muerto por el hecho de ser mujer. Aquí, entonces, la condición de mujer se obtiene por ser muerta, pero eso no es todo: tiene que ser por un hombre con quien haya tenido relaciones familiares o de convivencia, actuales o pasadas. La mujer, por tanto, no es sinceramente protegida en su condición de tal (de lo contrario la prohibición diría algo como "quien mate a una mujer será responsable de femicidio" sin condiciones relacionales), sino que se protege la institución superior que la absorbe, o sea, la familia: el bien jurídico protegido es el orden de las familias.

Tal como en el aborto, el abandono de niños, la violación, el estupro, el infanticidio -lamentablemente-, el incesto o antiguamente el adulterio diferenciado, la sodomía o el rapto, el delito especial de femicidio sirve de escudo al orden de las familia. Los delitos sexuales del derecho penal tienen el poder de producir aquello que regulan, cuando construyen y modelan el cuerpo que castigarán, y lo pueden hacer porque normativizan el sexo y sexualizan las normas. Siguiendo a Judith Butler: "En este sentido pues, el "sexo" no sólo funciona como norma, sino que además es parte de una práctica reguladora que produce los cuerpos que gobierna, es decir, cuya fuerza reguladora se manifiesta como una especie de poder productivo, el poder de producir -demarcar, circunscribir, diferenciar- los cuerpos que controla". ${ }^{34}$

\footnotetext{
33 Toledo, Patsilí, “¿Tipifica... (nota 22), pp. 213-214.

${ }^{34}$ Butler, Judith, Cuerpos (nota 32), p. 18.
} 
La elección por la protección de un determinado tipo de "mujer" en la implantación en nuestro sistema jurídico del delito de femicidio se corresponde con una idea determinada de la importancia que para la sociedad tiene la institución familiar y una correlativa deformación de las relaciones sociales, debido a la resignificación de la división de géneros y la asignación de roles arquetípicos a cada uno de los sujetos que portan con el sexo correspondiente. Se hace vigente la tradicional idea de derecho penal que dice: "Tradicionalmente se ha pensado que la libertad, el honor, el pudor, la honestidad, la moral o cualquiera otro valor similar, merece mayor protección en la mujer que en el varón. Por razones genéticas, fisiológicas, culturales, religiosas, ambientales, se ha entendido que el acto sexual puede tener mayores repercusiones en el sexo débil que en el hombre". ${ }^{35}$

El discurso se llena de anquilosadas ideas de división sexual, machismo y misoginia, cuando las mujeres son consideradas el sexo débil, las víctimas y los objetos de protección. Si el problema, en algún momento, fue de conceptualización de una problemática social dentro de un programa político de visibilización de la violencia simbólica y material ejercida en contra de mujeres, al momento de enunciar los fundamentos ello se derrumba.

Algunas autoras han considerado que este problema, el de la creación de una víctima súper-débil para luego protegerla, debe ser superado desde la perspectiva femenina y asumir una sincera apreciación del significado de cometer un homicidio en contra de otro en "razón de su sexo o su género". Así, se han propuesto conceptualizaciones de delitos como el genericidio ${ }^{36}$ que abriría las puertas al entendimiento de un delito especial de homicidio (no de parricidio) cometido en contra de una persona por pertenecer a un determinado sexo/género, o sea que en este mundo una mujer puede ser considerada responsable por la muerte de un hombre por ser éste un hombre, e incluso puede ser considerada responsable por la muerte de una mujer por ser ésta una mijer, sin la condición de que existan determinadas relaciones sociales o de parentesco conocidas entre los sujetos activo y pasivo de la relación jurídico-penal.

La empresa del genericidio, sin embargo, supone determinadas premisas en las que coincide con la matriz heteronormativa, pues si el sujeto víctima debe tener un género determinado, significa que ese género debe serle asignado de una determinada manera, lo que trae consigo la idea de un elemento subyacente que permita identificar ese género. Sea el sexo o no, la idea de asignar roles fijos y estáticos a los sujetos deviene un mecanismo de sistemática subjetivación y promueve el afán esencilizador que, como se ha mostrado, la ley de femicidio ya presenta. Si bien la existencia de un delito de genericidio es menos mala que la existente de femicidio (puesto que el genericidio, al menos, no da por presupuesto

\footnotetext{
${ }^{35}$ Martínez, Lisandro, Derecho penal sexual, Temis, Bogotá, 1977, p. 12.

${ }^{36}$ Cf. Vásquez, Carmina, No me lastimes con tus crímenes perfectos: del Genericidio al Masculinicidio, en CECU, En reversa. Primeras jornadas estudiantiles de teoría de género, Universidad de Chile, ed. Párrafo, Santiago, 2011.
} 
REJ - Revista de Estudios de la Justicia - No 16 - Año 2012

el género masculino ni su fuerza inherentemente superior al género femenino), ambos son un retroceso ante la libertad del sujeto.

\section{El incesto como prohibición matriz}

Las críticas mostradas pueden parecer un llamado a la anulación de la modificación realizada y hacer nada frente a los sucesos de asesinato sistemático de mujeres a manos de sus parejas. Pienso, de otra manera, que si bien no es la solución crear delitos especiales que funcionen con la matriz heteronormativa del género, esta sí constituye la explicitación de un problema social que aqueja a un conjunto de sujetos. El lenguaje jurídico, expresado mediante la ley, tiene un poder performativo de la realidad social que permite valorar de una determinada manera algunos hechos como hechos institucionales. Sin embargo, no hay que considerar como exitoso el reconocimiento de femicidios que evidentemente se dará después de la publicación de la ley, ya que antes no había formas de ver este delito en particular, pues bajo la postura del prevencionismo general y la función ejemplarizadora de esta modificación, no sería raro que se presentaran cifras que muestren la gran cantidad de hombres castigados por haber cometido femicidio.

Entonces, ¿qué hacer? Considero que existen muchos otros factores sociales que determinan en la ejecución de un femicidio, que van desde factores sociológicos constitutivos del sujeto, como los roles de hombre y mujer inculcados culturalmente, la consideración de la mujer como sexo débil, el llamado hecho al hombre para demostrarse superior en algún sentido; factores en los que incluso puede haber motivaciones económicas, tal como se argumenta que sucede en Ciudad Juárez: una gran cantidad de hombres cesantes asesina sistemáticamente a las mujeres que les quitan el trabajo, por ser este más barato y eficiente.

Aunque también considero que existen catalizadores a nivel jurídico-legal que promueven la existencia del femicidio como hecho social. Un conjunto de situaciones jurídicas que sostienen un mundo desigual y dan existencia a la división y jerarquización de las personas por elementos como su "sexo". Entre tales situaciones, considero que tienen una fuerza política y modeladora:

a) La situación legal de la "familia" en nuestra legislación, que debido a su silencio legislativo se presta para la constitución de una familia moldeada según estándares restrictivos sujetos a la interpretación social fundada en una matriz heteronormativa;

b) La prohibición del aborto que, como problema biopolítico, sustenta toda la base de su discutibilidad en propuestas corporales de la fisiología femenina y la diferencia entre "ella" y el no-nato; y

c) La persistente prohibición del delito de incesto en nuestro código penal, a la cual me referiré a continuación. 
El Código Penal chileno consagra en su artículo 375 el tipo del incesto. Dice: "El que, conociendo las relaciones que lo ligan, cometiere incesto con un ascendiente o descendiente por consanguinidad o con un hermano consanguíneo, será castigado con reclusión menor en sus grados mínimo a medio”.

En relación con ello, la pregunta fundamental está dada por los orígenes de un delito de estas características. El incesto, en el código penal vigente, está inserto en un apartado exclusivo que le contiene ("Del incesto"), situación que sucede sólo desde la modificación del año $1999,{ }^{37}$ pues antes de eso el incesto estaba mezclado con otros delitos bajo la rúbrica "Del estupro, incesto, corrupción de menores y otros actos deshonestos", junto con el antiguo delito de sodomía, encontrándose todo ello bajo el título de "crímenes y simples delitos contra el orden de las familias y contra la moralidad pública". ${ }^{38}$ En torno a la presencia de este delito en el sistema jurídico chileno vigente, cabe elucidar algunos de sus elementos y su naturaleza, es decir, (1) en qué consiste un "incesto" -ya que en el artículo se da como supuesto lingüístico- y cuáles son sus presuposiciones lingüísticas y sociológicas, (2) por qué es un delito, o más bien, cuál es el bien jurídico que protege y, en relación con esto, (3) los parecidos [bio]políticos que esta norma presenta en relación la fórmula del femicidio.

El incesto denotativamente es descrito, según la Real Academia de la Lengua (RAE), como la "relación carnal entre parientes dentro de los grados en que está prohibido el matrimonio", 39 versión del concepto que no agrega mucho a lo requerido para elucidar el concepto legal, pues podemos evidenciar que no son un elemento estructural de la definición los grados de parentesco del acto, a saber, la ley de matrimonio civil de Chile, ${ }^{40}$ en su artículo $6^{\circ}$ dice: "No podrán contraer matrimonio entre sí los ascendientes y descendientes por consanguinidad o por afinidad, ni los colaterales por consanguinidad en el segundo grado".

El incesto en nuestro sistema jurídico, por tanto, no contempla un espectro de aplicación idéntico al definido por la RAE, pues si bien suegra y yerno no pueden contraer matrimonio, sí pueden sostener relaciones sexuales sin cometer el delito de incesto. ${ }^{41}$ Ahora bien, el delito es descrito en función de la comisión de incesto, no de otro tipo de conducta sexual; la comisión de un incesto no está determinada por el grado de parentesco entre los sujetos participantes, toda vez que se delimitan distancias de parentesco sobre las que se puede cometer un incesto y no un conjunto de conductas que se describan en función del

\footnotetext{
${ }^{37}$ Ley 19.617, 1999, art. 1, Nos 24 y 25.

38 Actualmente se incluyen también, en ese título, los crímenes y simples delitos contra la integridad sexual.

${ }^{39}$ Ver incesto, diccionario de la RAE: http://buscon.rae.es/draeI/SrvltConsulta?TIPO BUS=3\&LEMA=incesto

${ }^{40}$ Ley 19.947, 2004, art. 6.

${ }^{41}$ Suegra y yerno (o suegro y nuera) están relacionados por parentesco según afinidad, grado que no está contemplado en el delito de incesto.
} 
parentesco. Parece como si faltara una descripción previa al incesto, la de cómo se realiza un incesto. Por lo cual la pregunta es: ¿existe alguna modalidad del incesto que no sea delictiva?, o más precisamente, ¿cuál es la forma en que un yerno con su respectiva suegra se comportan para ser descritos como agentes de un incesto? La RAE nos remite a una "relación carnal", por lo cual, en sentido jurídico, deberíamos remitirnos al concepto empleado por el legislador de "acceso carnal".

El acceso carnal, como especie de las "acciones sexuales" contempladas en el artículo 366 ter. del código penal, ${ }^{42}$ se refiere a la penetración que se realiza con el pene a alguno de los agujeros preferidos por el legislador: ano, vagina o boca. ${ }^{43} \mathrm{Si}$ bien, no es requisito que el sujeto activo de la acción sexual sea un hombre ${ }^{44}$ (en el incesto sujeto activo y pasivo se confunden), sí subsiste una evidente idea heteronormativa-victoriana de la sexualidad. Tal cuestión es enunciada por Etcheberry: "El código no ha definido lo que es 'cometer incesto'. Partiendo de la base de que existe una relación carnal debe dilucidarse si los incestuosos han de ser siempre personas de diferente sexo, y si los actos entre ellos realizados deben consistir en la cópula normal, o si pueden ser también actos de acceso carnal anormal o de homosexualidad". 45

La sexualidad, y desde allí las acciones sexuales y el acceso carnal, es un concepto masculinizado, ${ }^{46}$ y por tanto heteronormado. Ello quiere decir, en otra capa, que la sexualidad está "generizada" en función de una matriz heterosexual, concibiendo como existentes sólo las relaciones sexuales heterosexuales en que existe división y jerarquización sexual de los sujetos con un predominio de los faloportadores de aquellos que no tienen falo, o sea, de "hombres" sobre "mujeres". La exclusión de sujetos está dada en términos de heterosexualidad, o sea que no se concibe la comisión del delito de incesto, por ejemplo, por una pareja de lesbianas (nuera y suegra no cometen incesto cuando tienen una relación sexual). Esto porque no se entiende que pueda existir acceso carnal cuando dos mujeres, por ejemplo, se masturban recíprocamente, si bien tal acto puede ser considerado una acción sexual en tanto es un acto de significación sexual.

Es en la prohibición denominada "incesto" en donde encontramos uno de los más fuertes prismas que sostienen la matriz heteronormativa de pensamiento, comprensión y explicación del mundo. El delito de incesto, por tanto, está

\footnotetext{
42 Artículo 366 ter. "Para los efectos de los tres artículos anteriores, se entenderá por acción sexual cualquier acto de significación sexual y de relevancia realizado mediante contacto corporal con la víctima, o que haya afectado los genitales, el ano o la boca de la víctima, aun cuando no hubiere contacto corporal con ella."

43 Garrido, Mario, Derecho penal. Parte especial. Tomo III, Editorial Jurídica de Chile, Santiago 2007, pp. 338 y ss.

${ }^{44}$ Ibid., pp. 342-343.

45 Etcheberry, Alfredo, Derecho Penal. Parte Especial. Tomo IV, Editor Carlos E. Gibbs, Santiago, 1965 , p. 44.

${ }^{46}$ Cf. Mackinnon, Catherine, "Sexuality", en: Toward a Feminist Theory of the State, Harvard University Press, Massachusetts, 1987, pp. 127-154.
} 
determinado por la presencia de a lo menos un faloportador que permita el acceso carnal en el agujero (boca, ano, vagina) de un otro-pariente, según los grados de parentesco estipulados en el artículo 375.

Es así como la existencia del incesto presupone la heterosexualidad de nuestra sociedad, además de un determinado entendimiento de aquello que denominamos "lo familiar". A partir de esta prohibición se articulan la familia, el parentesco y la sexualidad permitida. Lo interesante del incesto en relación a lo anterior es que es sólo una calificación normativa de un hecho permitido en la conducta social: el incesto no es más que una relación sexual consentida. La violación consiste en una relación sexual, pero sin el consentimiento del sujeto pasivo de la acción, siendo su bien jurídico protegido la libertad de autodeterminación sexual y la intangibilidad sexual de la víctima; ${ }^{47}$ el incesto tiene como base un estándar objetivo (hecho) y subjetivo (conciencia de comisión de los sujetos) que lo presentarían como un suceso permitido, pero es un delito por las relaciones de los sujetos participantes, constituyéndose en una prohibición de carácter general. ¿Por qué?, ¿qué bien jurídico se protege?

Los señores licenciados don Juan Luis Monsalve y don Pablo Velozo, en su trabajo "El incesto, ¿un delito todavía?", formulan la pregunta por el bien jurídico que protege la prohibición del incesto. Analizan posibles bienes, que se van descartando hasta concluir que lo que se protege es el orden de las familias. Así, no se protege la libertad sexual de las personas, porque no requiere del abuso de un sujeto por sobre otro, pues, al contrario, presupone consentimiento de ambos participantes, siendo ambos infractores de la prohibición; tampoco protegería la moralidad pública, sino que consagraría una determinada y reducida concepción de la moral, a saber, aquella en que es considerado como malo el incesto; las razones eugénicas, fundadas en el discurso científico, son débiles ya que en un sentido sistemático-jurídico una mejor solución ante el problema del posible nacimiento de personas con deformidades producto de una relación sexual endogámica es el aborto (eugénico). ${ }^{49}$ Además, este último argumento no se condice con la libertad de las personas de tener hijos con deformidades, bajo su propia voluntad.

La prohibición del incesto, por tanto, estaría protegiendo la institución de la familia, pues es un atentado directo en contra del matrimonio: no sería necesario contraerlo para constituir familia, puesto que los delincuentes serían familia por un hecho previo (serían hermanos, por ejemplo). Visto desde una perspectiva económica, el flujo sexual de los cuerpos estaría siendo estancado pues cada cual

\footnotetext{
${ }^{47}$ Garrido, Mario, Derecho Penal (nota 43), p. 335.

48 Monsalve, Juan Luis y Velozo, Pablo, El incesto, ¿un delito todavia?, Memoria para optar al grado de licenciado en ciencias jurídicas y sociales, Facultad de Derecho, Universidad de Chile, Santiago, 2001.

49 Politoff, Sergio, Grisolía, Francisco y Bustos, Juan, Derecho penal chileno. Parte especial, Editorial Jurídica de Chile, Santiago, 1971, pp. 237-238.
} 
no tendría que salir de su casa para llevar una vida moralmente válida. Tradicionalmente, además, se defiende esta idea de que el bien jurídico protegido es el orden de las familias: "Al proteger el legislador el 'orden de las familias', se refiere a un bien jurídico que no pertenece a una persona sola, ni tampoco a la sociedad en general, sino a un grupo de personas que forma la base de la organización social: la familia [...] El orden de las familias ha sido considerado por el legislador bajo un doble aspecto: ante todo, el respeto a la constitución jurídica de la familia y a las relaciones de este carácter que de ella nacen, y en segundo lugar, el recto uso de la función sexual de acuerdo con las normas jurídicas que rigen la constitución de la familia y de acuerdo con las reglas sociales y biológicas que el legislador ha estimado conveniente proteger". ${ }^{50}$

Las explicaciones del origen de la prohibición del incesto, producidas teóricamente desde el psicoanálisis por Freud y Lacan, o desde la antropología por Malinowski y Lévi-Strauss, tanto por una explicación desde el inconsciente como desde las estructuras fundamentales de la cultura, presentan el problema desde conflictos prístinos traducibles como luchas por el reconocimiento: hombres que aman a la madre y ven en el padre un rival del cual deben deshacerse, y no deben copular con la madre viuda a fin de no repetir el parricidio original ${ }^{51}$; relaciones simbólicas entre significante y significado; función constituyente de mitos estructurales; o ritos protojurídicos que se erigen en la repetición. Todas las tesis, sin embargo sostienen una constante prohibición de ciertas prácticas sexuales que ni siquiera pueden ser comprendidas como "sexuales" debido a la función ideológica de la matriz heteronormativa.

\section{La crítica desde el posfeminismo}

El problema de la tipificación especial de un delito de femicidio puede presentarse como una circunstancia política crítica si se mira desde una posición postfeminista, pues se erige como un sustento más de la matriz héteronormativa que constituye y esclaviza a los sujetos de modo performativamente político.

El género asignado a los sujetos, como fuente de determinación del mismo, es performativo, lo que significa que el "género se construye a través de un conjunto sostenido de actos, postulados por medio de la estilización del cuerpo basado en el género". ${ }^{2}$ Lo que se considera algo inherente al cuerpo de las personas, en el fondo, es una circunstancia contingente fundada en elementos estéticos, es decir que, siguiendo a Butler: "Tal vez creemos saber cuál es la anatomía de la persona (a veces no, y con seguridad no hemos reparado en la variación que hay en el nivel de la descripción anatómica). $\mathrm{O}$ inferimos ese

\footnotetext{
${ }^{50}$ Etcheberry, Alfredo, Derecho Penal (nota 45), pp. 11-12.

${ }^{51}$ Cf. Vázquez, Héctor, Del incesto en psicoanálisis y en antropología, Fondo de Cultura Económica, México D.F., México, 1986, pp. 19-21.

52 Butler, Judith, El género (nota 12), p. 17.
} 
conocimiento de la vestimenta de dicha persona, o de cómo se usan esas prendas". ${ }^{53}$ En definitiva, es conflictivo definir los límites y utilidades (incluso desde un punto de vista estrictamente feminista) de la creación de nuestro mentado tipo especial, principalmente porque "no existe una identidad de género detrás de las expresiones de género; esa identidad se construye performativamente por las mismas 'expresiones' que, al parecer, son resultado de ésta". ${ }^{44}$ Finalmente, la construcción del sujeto mediante la prohibición determina la construcción de un deseo heterosexual: la mujer es lo no-hombre y, como tal, la otredad. El femicidio, por tanto, fortalece la situación de una división sexual y jerarquización de los sexos, enmascarada en tácticas antiviolencia de género, pero que en definitiva no hacen sino excluir sujetos en pos de una política heterosexualizante de la sociedad, que termina por defender los mal llamados "valores" de la sexualidad correcta, la moral pública y el orden de las familias, en un juego de lenguaje que debería considerarlos como opciones dentro de la libertad individual.

Así, el deslizamiento desde la problemática de la norma que castiga el femicidio hacia la del cuestionamiento de la persistente prohibición del incesto, es fundamental. En síntesis, y siguiendo a Judith Butler, debemos tener en cuenta que "las prohibiciones que funcionan para prohibir el intercambio sexual no normativo también funcionan para instituir y vigilar las normas del presunto parentesco heterosexual". ${ }^{55}$ Y con eso, caemos de vuelta en el problema de la concepción social de la familia y toda la problemática que ya tratamos $s u p r a^{56}$, ya que "¿cómo sino puede comprenderse la prohibición de las relaciones sexuales con miembros de la propia familia sin una concepción previa de la familia?."57

\section{Consideraciones finales}

La ley que tipifica el delito de femicidio como un crimen autónomo presenta, en último término, la misma justificación normativa que la anacrónica prohibición del incesto, fundada en argumentos míticos, patriarcales y heteronormativos. El sistema jurídico-conceptual que requiere la creación de un delito de femicidio no se da en un contexto de democracia ni liberalismo, pues requiere de la creación desigual de la forma en que las mujeres deben ser.

Menos que defender, desde un punto de vista feminista, como resistencia política ante la dominación masculina, la tipificación especial del femicidio fortalece la idea de una estructura fija y estática de la sexualidad y del cuerpo, endureciendo las bases de una praxis de exclusión política y ciudadana de determinados sujetos. Quienes no desempeñen el rol exhortado por el sistema de

\footnotetext{
53 Ibid., p. 27.

54 Ibid., p. 85.

${ }^{55}$ Butler, Judith, Deshacer (nota 23), p. 224.

${ }^{56}$ Cf. Sección 4 de este trabajo.

${ }^{57}$ Butler, Judith, Deshacer (nota 23), p. 224.
} 
REJ - Revista de Estudios de la Justicia - No 16 - Año 2012

constitución de los sujetos sufrirán las penas de la inclusión por exclusión $;^{58}$ los anormales o abyectos son considerados la cara oscura de los que ejecutan sexualidades permitidas.

Es interesante considerar, sin embargo, el rol subversivo de aquel que está en los márgenes de la normalidad jurídica, pues su potencia deconstructora del sistema de prohibición se presenta como la opción sobre la cual debe [per]formarse la norma que superará al error político cometido con la publicación de la ley de femicidio.

No parece ser racional crear un delito especial fundado en una determinada descripción de un delito tan sólo por su repetición constante: la mayoría de los delitos de "femicidio" son cometidos mediante el uso de arma blanca, y no por ello vamos a tipificar un delito de "femicidio con arma blanca" distinto de uno que se realice por otro medio.

La función del acto político de distinguir un delito como especial debiera estar fundada en los motores de la libertad del sujeto, en el sentido de reconocer un uxoricidio o asesinato de una pareja (sexual o ritual, como es el o la cónyuge) es un delito agravado en consideración con un parricidio simple. Debe reconocerse la validez de una mujer asesina de otra mujer por ser esta su pareja, debe reconocerse la posibilidad de convivencia polígama entre muchos sujetos relacionados amorosamente. De lo contrario, las relaciones sociales se reducen hasta que llegan a ser un punto cercano a la inexistencia.

Para terminar, me gustaría recordar una cita de Michel Foucault, en relación con el empobrecimiento de las relaciones sociales que se sustentan día a día: “[...] Vivimos en un mundo legal, social e institucional donde las únicas relaciones posibles son extremadamente escasas, esquemáticas y pobres. Existe, por supuesto, la relación del matrimonio y las relaciones de familia, ipero cuántas otras deberían existir!". ${ }^{99}$ En esta cita se refleja una idea: el ánimo de multiplicación antes que de prohibición; considerar la tipificación del femicidio como el triunfo es en sí una derrota.

\footnotetext{
${ }^{58}$ Cf. Agamben, Giorgio, Homo sacer. El poder soberano y la nuda vida, ed. Pre-textos, Valencia, 2010, p. 35.

${ }^{59}$ Foucault, Michel, "La amistad como modo de vida", en Halperin, David (ed.) San Foucault. Para una hagiografía gay, El Cuenco de Plata, Córdoba, Argentina, 2007, pp. 103-104.
} 
Ried - Un delito propio. Análisis crítico de los fundamentos de la ley de femicidio

\section{BIBLIOGRAFÍA}

* Agamben, G.: Homo sacer. Elpoder soberano y la nuda vida, ed. Pre-textos, Valencia, 2010.

* BUtler, J.: Cuerpos que importan, $2^{\mathrm{a}}$ ed., Paidós, Bs. Aires, 2008. El género en disputa, Paidós, Barcelona, 2007.

Deshacer el género, Paidós, Barcelona, 2006.

Violencia de Estado, guerra, resistencia. Por una nueva política de la izquierda, ed. Katz, Madrid, 2011.

* DE LAS HERAS, S.: "Una aproximación a las teorías feministas". Universitas. Revista de Filosofía, Derecho y Politica, No 9, enero 2008.

* ETCHeberry, A.: Derecho Penal. Parte especial. Tomo IV, editor Carlos E. Gibbs, Santiago 1965.

* Ferrajoli, L.: Derecho y Razón. Teoría del garantismo penal. Ed. Trotta, Madrid, 2001.

* FOUCAUlT, M.: Historia de la sexualidad. La voluntad del saber, vol. 1, ediciones Siglo XXI, Buenos Aires, 2008.

Elpensamiento del afuera, $5^{\mathrm{a}}$ ed., Pre-textos, Valencia, 2004.

La verdad y las formas jurídicas, Gedisa, Barcelona, España, 2001

* GARrido, M.: Derecho Penal. Parte especial. Tomo III, Editorial Jurídica, Santiago, Chile. 2007.

* HalPerin, D.: San Foucault. Para una hagiografía gay, ed. El Cuenco de Plata, Córdoba, Argentina, 2007.

* MACKINNON, C.: "Sexuality", en: Toward a Feminist Theory of the State, Harvard University Press, Massachusetts, 1987.

* MAÑAliCH, J. P.: Terror, pena y amnistía, ed. Flandes Indiano, Santiago, Chile, 2010. "Ontología sexual y derecho penal"; en: En reversa. Primeras jornadas estudiantiles de teoría de género, Universidad de Chile, ed. Párrafo, Santiago, 2011.

“La pena como retribución”, en Revista de Estudios Públicos, Santiago, N 108, 2007.

* MARTÍnEZ, L.: Derecho penal sexual. Editorial Temis, Bogotá, Colombia, 1977.

* MerA F., J.: "Femicidio", en: Tipificación del femicidio en Chile. Un debate abierto, Andros, Santiago, 2009.

- MONSAlve, J. L. y VElOZO, P.: El incesto, ¿un delito todavía?. Memoria para optar al grado de licenciado en ciencias jurídicas y sociales, Universidad de Chile, Facultad de Derecho. Santiago, Chile, 2001.

* PATERnOTTE, D.: "Matrimonio 'homosexual' y ciudadanía: la hipótesis de la resignificación", en Revista Nomadías, Santiago, 2012, de http://www.revistas.uchile.cl/index.php/NO/article/viewArticle/15131/15548

* POlitofF, S., GRISOLÍA, F. y BUSTOS, J.: Derecho Penal Chileno. Parte especial. Editorial Jurídica, Santiago, Chile, 1971.

* RIED, N.: "Venciendo a Procusto. El concepto de familia: el feminismo liberal, el postfeminismo y el problema del género", en Revista Derecho y Humanidades, Santiago, Chile. Universidad de Chile, Facultad de Derecho. N 17, 2011.

"Familia y prohibición. Genealogía de las prohibiciones jurídico-morales en materia sexual". En CECU. En reversa. Primeras jornadas estudiantiles de teoría de género, ed. Párrafo, Santiago, 2011.

* RUSSELL, D.: "Conclusión feminicidio: la 'solución final' de algunos hombres para las mujeres”; en su: Femicidio: una perspectiva global, UNAM, México, 1992.

* TOlEDO, P.: “¿Tipificar el Femicidio?”, en Anuario de Derechos Humanos No 4, Centro de Derechos Humanos, Facultad de Derecho de la Universidad de Chile, Santiago, 2008.

"Leyes sobre femicidio y violencia contra las mujeres. Análisis comparado y problemáticas pendientes", en Tipificación del femicidio en Chile. Un debate abierto, Andros, Santiago, 2009. 
REJ - Revista de Estudios de la Justicia - No 16 - Año 2012

* VÁsQuez, C.: "No me lastimes con tus crímenes perfectos: del Genericidio al Masculinicidio", en: CECU. En reversa. Primeras jornadas estudiantiles de teoría de género, Universidad de Chile, Ed. Párrafo, Santiago, 2011.

- VÁZQUEZ, H.: Del incesto en psicoanálisis y en antropología, Fondo de Cultura Económica, México D.F., México, 1986. 